\title{
Per-visit pollinator performance and regional importance of wild Bombus and Andrena (Melandrena) compared to the managed honey bee in New York apple orchards
}

\author{
Mia G. PARK ${ }^{1,2}$, Robert A. Raguso ${ }^{3}$, John E. Losey ${ }^{1}$, Bryan N. Danforth ${ }^{1}$ \\ ${ }^{1}$ Department of Entomology, Cornell University, Ithaca, NY, USA \\ ${ }^{2}$ Departments of Humanities \& Integrated Studies and Biology, University of North Dakota, Grand Forks, ND, USA \\ ${ }^{3}$ Department of Neurobiology and Behavior, Cornell University, Ithaca, NY, USA
}

Received 3 December 2014 - Accepted 9 July 2015

\begin{abstract}
Declines in honey bee health and increasing demand for pollination services highlight a need to optimize crop pollination by wild bees. Apple is an economically important crop in eastern North America, requires insect pollination, and is visited by a diverse bee fauna, but a direct assessment of wild bee pollination in apple orchards is lacking. We combined measurements of two facets of pollination service, per-visit efficiency (fruit and seed set) and relative abundance, to estimate orchard-level, pollinator importance of mining bees (Andrena subgenus Melandrena), bumble bees (Bombus), and honey bees (Apis mellifera L.). Average pollinator importance provided a relative measure that allowed comparison of pollination service among the three focal bees across the study region. On average, a wild bee visit resulted in higher pollen transfer to stigmas, but had the same probability of setting fruit and seed as a honey bee visit. Regionally, pollinator importance of Melandrena and Bombus were 32 and $14 \%$ that of honey bees, respectively. Because per-visit performances were similar, such disparities in importance were based largely on differences in relative abundance. Although the summed pollinator importance of Melandrena and Bombus was less than that of the honey bee, these, and other, wild pollinators have a role to play in filling future pollination gaps, and thus, warrant further study and conservation.
\end{abstract}

native bee / Apis mellifera / reproductive success / crop pollination

\section{INTRODUCTION}

Animal pollination is essential for sexual reproduction of many wild flowering plants and agricultural crops. Apple (Malus domestica Borkh.) is an economically important crop that is varietally self-incompatible and requires crosspollination by insects, mostly bees, to set a commercially viable crop (Free 1993; McGregor 1976). Apple fruit quality is also influenced by insect pollination. Inadequate pollination can cause low seed set and empty carpels resulting in

Corresponding author: M. Park, mia.park@und.eduG.

Park, mia.park@und.edu

Manuscript Editor: James Nieh small or asymmetric fruit with low market value and low mineral content which reduces shelf life (Garratt et al. 2014; Sheffield 2014). To ensure commercial quality fruit and yields, New York apple growers commonly rent honey bees (Apis mellifera L., hereafter referred to as Apis), with hive densities ranging from 0.4 to 2.8 hives per hectare in our study region, at US\$65-85 per hive (Eve Consulting unpubl. data; Park et al. 2015). However, colony losses due to "Colony Collapse Disorder" in North America and competing pollination demands have fueled increased hive rental fees and supply shortages for apple growers (Oldroyd 2007; vanEngelsdorp et al. 2009). Inadequate Apis supplies have already been linked with sub-optimal production of highly pollinator-dependent crops, including high 
bush blueberry, gala apples, and oilseed rape (Benjamin and Winfree 2014; Breeze et al. 2014; Garratt et al. 2014). The threat of pollinator shortages due to continuing declines in Apis highlights a need to examine alternative pollinators for apple.

Apple is visited by a diverse wild bee fauna in central New York (Gardner and Ascher 2006; Park et al. 2015; Russo et al. 2015). Recent work showing the positive influence of wild bee species richness and functional diversity on apple production and quality indicates that wild bee communities contribute significantly to apple pollination (Mallinger and Gratton 2015; Martins et al. 2015). In terms of abundance, wild bee communities are dominated by mining bees (40\%, genus Andrena) and queen bumble bees (4\%, genus Bombus), active in spring when apple blooms (Russo et al. 2015). Among Andrena, species in the subgenus Melandrena (hereafter, referred to as Melandrena) seem potentially important apple pollinators due to their large body size, early spring phenology, and abundance in eastern orchards (Brittain 1933; Gardner and Ascher 2006; Park et al. 2010; Phillips 1933; Watson et al. 2011). Moreover, Melandrena may prefer apple flowers to co-blooming alternatives, as andrenids are found to carry large quantities of apple pollen on their bodies (Gardner and Ascher 2006; Kendall and Solomon 1973). Apple growers generally consider Bombus bees as good pollinators for their ability to forage in low temperatures, common during apple's spring bloom (Brittain 1935). Bombus bees transfer more pollen to apple stigmas than Apis because they frequently contact stigmas while foraging (Thomson and Goodell 2001). Similarly, andrenids contact the stigmatic surface of McIntosh apple flowers more than Apis (Martins et al. 2015). Additionally, andrenids store dry pollen in scopal hairs near their hind coxae, increasing the likelihood that pollen will be transferred to the stigma upon contact (Thorp 2000). In contrast, Apis and Bombus store moistened pollen in corbicula, making pollen generally unavailable for pollination (Westerkamp 1991). Despite indirect evidence that both Melandrena and Bombus are good pollinators of apple, previous studies have not documented per-visit contributions of specific wild pollinators to apple's reproductive success nor have previous studies quantified their regional importance in apple pollination (for exception, see Brittain 1933).

To address these knowledge gaps, the goals of this study were twofold: (1) provide a reliable comparison of per-visit pollination performance among Melandrena, Bombus, and Apis and (2) quantitatively compare pollination services of the three focal bees in central New York apple orchards by scaling up per-visit performance to the orchard level. Aside from comparing foraging behaviors and pollen carried by pollinators (as described above), pollination ecologists rely heavily on pollen deposition as a proxy for per-visit performance of pollinators in pollination studies, including those focused on crops, due to the relative ease of collecting such data (e.g., pumpkin, Hoehn et al. 2008; blueberry, Javorek et al. 2002; watermelon, Kremen et al. 2002; Pak-choi, Rader et al. 2009; coffee, Ricketts 2004; and apple, Thomson and Goodell 2001). Unfortunately, pollen transfer does not translate completely to reproductive success (i.e., fruit set or seed set), arguably a more accurate measure of a pollinator's performance (Cane and Schiffhauer 2003). First, the relationship between pollen deposition and reproductive success likely follows a nonlinear saturation function with a maximum optimal threshold (Harder and Thomson 1989). Second, for self-incompatible plant species, like apple, the use of pollen loads is further complicated by an observer's inability to distinguish self from crosspollen (Snow 1982). Ideally, one could measure fruit and seed set from a single or multiple visits as has been done for crops like pumpkin (Artz and Nault 2011); however, because apple produces a mass display of blossoms, the odds of a visitor landing on a single flower under observation is low, rendering this method impractical during apple's short bloom period. Counting only viable pollen grains, by assessing pollen tube growth, has been effectively used for massblooming almond to look at pollinator performance, but such methods require specialized equipment and skill (Brittain et al. 2013). Here, we employ an alternative method that experimentally establishes relationships between stigmatic pollen 
deposition and fruiting response (Cane and Schiffhauer 2003). Ne'eman et al. (2010) distinguish a pollinator's ability to transfer pollen from its ability to initiate a fruiting response as per-visit effectiveness and efficiency, respectively. We adopt these terminologies here and, ultimately, rely on per-visit efficiency as our measure of per-visit performance.

To investigate regional pollination services of wild bees in comparison to honey bees for apple within central New York State, we scaled up pervisit efficiency to orchard-level pollinator importance. Pollinator importance is the relative contribution of a floral visitor to the pollination of a plant population (here, an orchard), and incorporates two components of pollination service: pervisit performance and relative abundance (Olsen 1996; Rader et al. 2009). Pollinator importance scales up per-visit performance by accounting for the fact that an abundant pollinator with a low pervisit impact on pollination may contribute as much, if not more, to overall pollination as a rare pollinator that has high per-visit impact. When considering how much insurance alternative pollinators could provide given future Apis shortages, accounting for differences in abundance provides a more informative index of pollination service than per-visit measures of performance alone.

\section{MATERIAL AND METHODS}

\subsection{Study sites and organisms}

To quantify pollinator effectiveness, we recorded rates of per-visit pollen deposition by free flying pollinators during May 2010 at Cornell University's experimental orchard (CU), Ithaca, New York (lat $42.444808^{\circ}$, long $-76.462345^{\circ}$ ). In spring 2011 , to estimate per-visit efficiency from per-visit effectiveness we developed functional relationships between pollen deposition and reproductive success at $\mathrm{CU}$ and at a commercial orchard near Berwick, Nova Scotia (NS, lat 44.98396, long -64.78479), using hand-applied bees (see Table I for overview of experiments conducted). To eliminate differences in pollinator behavior among apple varieties due to flower morphology, we used "Honeycrisp" throughout the study. At both orchards, experiments were conducted on two rows of
Honeycrisp trees, grown on dwarf rootstock. Tree and row spacing were similar at study orchards: experimental rows were flanked by co-blooming varieties; however, varieties of adjacent rows differed among study sites. Apis hives were present at both study sites, with hive densities of 0.7 and 3 hives per hectare at CU and NS, respectively. Bee surveys in 16 and 19 orchards in 2011 and 2012, respectively, throughout central New York provided relative abundance data used to scale per-visit efficiency up to pollinator importance at the orchard level.

\subsection{Relative abundance}

We quantified pollination services at the regional level, using pollinator importance as our framework (Olsen 1996). Here, pollinator importance is the product of (1) visitation frequency of floral visitors and (2) pervisit efficiency (Rader et al. 2009; Vázquez et al. 2005). We used relative abundance as a proxy for visitation frequency, as justified by Gallai et al. (2009). We surveyed orchards and collected apple-visiting bees during bloom in spring 2011 and 2012 throughout central New York (Park et al. 2015). All bees observed on apple blossoms were net-collected along transects that spanned both sides of two adjacent tree rows for $15 \mathrm{~min}$. Collecting occurred during peak bee activity between 1000 and 1500 hours, with temperatures above $16{ }^{\circ} \mathrm{C}$. For each bee group, we calculated average abundance per collecting event at each orchard per year. We divided the average abundance for each bee group by the total average abundance of all three bee groups included in the study to calculate relative abundances of focal bees. Due to non-normality of data, we used nonparametric Kruskall-Wallis tests to explore differences in relative abundance and non-parametric Wilcoxon rank-sum post hoc tests to further explore differences between bee groups. Experiment-wise error was controlled using a post-priori Bonferroni correction.

\subsection{Free-foraging per-visit effectiveness and behavior}

Following Thomson and Goodell (2001), we compared per-visit effectiveness of Melandrena and Bombus to that of Apis, by quantifying pollen deposition from a single visit. Prior to opening, apple flowers were emasculated and bagged to prevent contamination from self-pollen and other insects, respectively. We 
Table I. Per-visit performance experiment locations and times. We provide an overview of the experiment goals and methods

\begin{tabular}{|c|c|c|c|}
\hline & & Cornell University orchard & Nova Scotia orchard \\
\hline \multirow[t]{2}{*}{2010} & Goal(s) & \multicolumn{2}{|c|}{ Measure per-visit pollen deposition and natural foraging behavior } \\
\hline & Method & $\begin{array}{l}\text { Interviews of free-foraging Apis, Melandrena, } \\
\text { and Bombus; observations of free-foraging } \\
\text { bees at natural flowers }\end{array}$ & NA \\
\hline \multirow[t]{2}{*}{2011} & Goal(s) & \multicolumn{2}{|c|}{ Establish relationship between per-visit pollen deposition and efficiency (fruit and seed set) } \\
\hline & Method & Hand application of Apis and Melandrena & $\begin{array}{l}\text { Hand application of Apis, } \\
\text { Melandrena, and Bombus }\end{array}$ \\
\hline
\end{tabular}

“interviewed" foraging bees between 0900 and 1900 on fair days, by offering them open, viable flowers attached to the tip of a $0.5-\mathrm{m}$ rod (Thomson and Goodell 2001). We used flowers that had visibly produced nectar, because it was difficult to get a bee to visit otherwise, with receptive stigmas (i.e., had not yet turned brown). A legitimate visit involved active foraging or direct contact with stigmas by the bee. Visits were timed and the following response variables recorded: visit duration, reward sought (pollen, nectar collection, or mixed), foraging approach (top, side, or mixed), and presence of pollen loads. Observing differences in foraging approach was of particular interest because side approaches, or "side-working," results in less stigmatic contact and, consequently, reduced per-visit seed set and fruit development (Robinson and Fell 1981). Sideworking is a well-documented behavior for honey bees and involves bees collecting nectar through stamen filaments by standing on a petal, thereby, avoiding contact with stigmas. Both Bombus and andrenids have been observed to contact stigmas more frequently than Apis, but this has not yet been documented for Melandrena, per se (Martins et al. 2015; Thomson and Goodell 2001). Visited stigmas were mounted on microslides, and pollen grains were counted at $\times 200$ magnification under a Leitz compound microscope. Because it is difficult to distinguish among species of Rosaceae based on pollen morphology alone, we categorized pollen as Rosaceae or other, with the assumption that Rosaceae pollen is largely apple since bees were foraging on apple trees and co-blooming Rosaceae were not observed adjacent to orchards. At NS apple was the only crop planted in the orchard; at $\mathrm{CU}$, another Rosacea crop, beach plum (Prunus maritima Marshall), was in bloom at the same time in the orchard, but its pollen grains were noticeably larger and were rarely observed on mounted stigmas. Pollen from coblooming flowers in the orchard understory was easy to distinguish from those of apple.

Because emasculated flowers were morphologically distinct from un-manipulated apple blossoms, we assessed differences in foraging behavior among focal bee groups by observing naturally foraging bees. Each bee was followed until it flew out of the observer's sight. At CU, in 2010 and 2011, we recorded the following for each foraging "bout": bee taxonomic identity, reward sought, approach, and time at each flower. To minimize influence of external factors (e.g., time of day and temperature), we alternated our observations among bee groups. In 2010, natural foraging observations were made concurrently with interviews.

We used descriptive statistics to compare frequencies of natural and "interview" foraging behavior. For interviews, we tested fixed effects of visitor, visit duration, presence of pollen loads, foraging approach, reward sought, and their interactions, on the response variable per-visit pollen deposition in a generalized linear model (GLM). Due to non-normality of pollen deposition data, we used a negative binomial distribution and checked for overdispersion (Zuur et al. 2013). We excluded Bombus from the GLM given its small sample size $(n=8)$. Bombus -included interview models kept presence of pollen load in, but removed visitor; while Bombus -excluded interview models kept visitor in but removed pollen load. Because there were so few mixed approaches (both top- and side-working) and rewards sought (both pollen and nectar), we reclassified them as top-working and pollen foraging, respectively, since both designations were predicted to maximize stigmatic contact and pollen deposition. Models were reduced by backwards step-wise selection: variables that were not significant $(P>0.05)$ and did not improve model fit, as 
determined by a log-likelihood ratio test, were removed (Zuur et al. 2013). Because the GLM excluded Bombus, a non-parametric Kruskall-Wallis test was used to compare pollen deposition among the three bee groups. As with all analyses in this study, the GLM was conducted in R version 3.1.2 software (R Foundation for Statistical Computing, Austria).

\subsection{Manual applications of bees}

To model relationships between per-visit effectiveness (pollen deposition) and efficiency (fruiting response), in May 2011, we hand-applied Apis and Melandrena treatments, as well as a positive control (100 \% cross pollen) to blossoms left on the tree to develop into fruit at both study sites (Kendall and Solomon 1973). Crab apple pollen for positive controls was collected $48 \mathrm{~h}$ prior to application, by placing anthers under a desk lamp in an open petri dish to dehisce. Viability of this pollen was confirmed by staining with lactophenol- $1 \%$ analine blue (Kearns and Inouye 1993). At NS, we also included a negative control (no pollen), a hand-applied Bombus treatment, and a pollen placement treatment to see if pollen stored in scopa and on the thorax differed in viability, as scopal pollen is considered unavailable for pollination (Westerkamp 1991). As with interview flowers, we prepared virgin, Honeycrisp blossoms by bagging and emasculating them prior to opening. At $\mathrm{CU}$, where poor weather conditions limited availability of viable blossoms, we randomly assigned bee and control treatments to blossoms. At NS, we performed a complete-block design where 29 trees were systematically selected from two adjacent rows. At each tree, eight flower clusters were randomly assigned a treatment (2 controls, 3 bee $\times 2$ pollen placement treatments). Each bee was collected by hand, directly from blossoms within experimental rows, with a clean, glass vial and immobilized by placing vials in ice. Using clean forceps to hold the bee, the underside of the thorax was applied gently, but directly, to stigmas for 5 seconds. The lateral, exterior edge of one scopa was similarly applied to stigmas of another flower cluster. The size of each bee's scopal pollen load was visually assessed ( $0=$ none, $1=$ less than $1 / 4$ full, $2=1 / 4-3 / 4$ full, $3=$ more than $3 / 4$ full). To control for maternal competition effects among fruits, clusters were thinned to just the one experimental blossom. All flowers were rebagged to ensure that fertilization and seed set resulted only from treatments.
Following similar procedures to interview flowers, we recorded per-visit pollen deposition by removing stigmas from treated flowers $48 \mathrm{~h}$ after pollination, mounting stigmas on microslides, and counting Rosacea pollen. To allow full fruit development, we did not re-bag flowers. One week after pollination, fruit set was recorded as the proportion of flowers that had developed into fruit. Two weeks after pollination and prior to chemical thinning, apple fruitlets were collected and the following recorded per fruit: fruitlet size, number viable seeds, and number carpels with one or more viable seed. For CU fruit, we measured fruit size as the diameter with a digital caliper and identified viable seeds as those actively growing (i.e., larger and fully inflated vs. small and shriveled). We were unable to similarly process NS fruitlets, as they were held up in international customs and arrived shriveled. We therefore recorded fruit size as dry weight (g) and identified seed viability by length, measured with a millimeter ruler at $\times 10$ on a Leitz stereoscope. A subsample of seeds was weighed, showing a strong correlation between length and mass. Seeds displayed a bimodal distribution, which guided a conservative cutoff length for viable seeds at $1.4 \mathrm{~mm}$. In fall 2011, we confirmed that this was a reasonable cutoff size for seed viability, by haphazardly harvesting mature Honeycrisp apples from the CU orchard in our experimental rows and measuring aborted seeds (mean $\pm 1 \mathrm{SD}, 1.44 \mathrm{~mm} \pm 0.79$ ).

Due to different experimental designs, the analyses for two study sites were conducted separately. To test fixed effects of visitor and pollen load size on pollen deposition (ln-transformed) from hand-applied bees, we ran normally distributed GLM and generalized linear mixed models (GLMM), respectively. We added pollen source (thorax or scopa) as a fixed factor and tree as a random blocking variable to the NS GLMM. Both models were reduced with stepwise backward deletion as described above. To compare pollen deposition among hand-applied bee groups, we performed pairwise, post hoc, Tukey's-adjusted tests after each model.

To characterize the functional relationships between per-visit pollen deposition of the various visitors and fruit and seed set, we conducted a series of parallel linear models with fruit or seed set as the response variable and with pollen deposition (ln-transformed), visitor, and their interaction as fixed factors. A 
significant interaction would indicate that the same pollen transfer by different bee groups resulted in different rates of fruit or seed set. The implication would be that bee groups vary in the quality of the pollen carried on their bodies. For CU data, we used a binomial GLM (i.e., logistic regression) to test relationships between fixed variables and fruit set; we were unable to construct a meaningful seed set model due to an inadequate sample size $(n=13)$ and relied exclusively on NS data to explore fruit quality (described below). For NS data, we conducted a binomial GLMM to test effects of fixed variables on the response fruit set. A random term consisting of the individual bees ID nested within tree was included to account for dependence among flowers that received pollen from thorax or scopa of the same bee and for dependence of flowers developing on the same tree. A similar, but normally distributed, GLMM with seed set as the response was also conducted. All models were reduced using backwards step-wise selection as described above. We used NS data to further explore visitor effects on fruit quality. We included in a normally distributed GLMM the response fruit weight (ln-transformed) and the fixed effects visitor, pollen deposited, and their interactions, with tree as a random grouping factor. We similarly tested the effects of the same predictor variables on the response number of carpels with developing seeds in a Poisson GLMM. Mean fruit set, seed set, and fruit weight were compared using post hoc pairwise Tukey's adjusted tests.

We verified that assumptions of normality and heteroscedasticity were met, and that Poisson and negative binomial models were not overdispersed. As mentioned previously, normal and binomial GLMMs were conducted in "nlme" (Pinheiro et al. 2014) and "lme4" (Bates et al. 2011) packages in R, respectively, and their degrees of freedom were derived using Penalized Quasi-Likelihood in R package 'MASS' (Venables and Ripley 2002).

With linear models that related pollen deposition to both fruit and seed set, we then translated pollinator effectiveness to a more meaningful and accurate measure of pollinator efficiency. Specifically, we used model equations to calculate expected pollinator efficiencies from pollen deposition rates recorded during interviews. Differences in estimated fruit and seed set among focal bees and between bee pairs were compared using non-parametric Kruskall-Wallis and non-parametric Wilcoxon rank-sum post hoc tests with Bonferroni correction, respectively.

\subsection{Importance}

We calculated Apis, Melandrena, and Bombus pollinator importance at the orchard level in 2011 and 2012 by the product of a bee group's relative abundance and per-visit efficiency. We used estimated fruit set as our measure of per-visit efficiency because seed set was highly correlated and fruit set has more direct implications for production. Additionally, fruit set estimates came from the NS (but not $\mathrm{CU}$ ) model given that at NS we had data for all three bee groups, a blocked study design, and higher sample size. Mean standard errors of importance were calculated by the delta method (Powell 2007). Statistical differences in pollinator importance among bees were tested as described above for estimated per-visit efficiencies.

\section{RESULTS}

\subsection{Relative abundance}

Study-wide, the relative abundance of bees differed significantly (Kruskall-Wallis, 2011: $\chi_{2}^{2}=25.63, P<0.0001 ; 2012: \chi_{2}^{2}=44.6119$, $P<0.001$ ), with Apis being more abundant than Bombus and Melandrena both years (Wilcoxon rank sum; all, $P<0.001)$, and Melandrena more abundant than Bombus in 2012 (Wilcoxon rank sum, $P=0.04$; Figure 1a). Relative abundance of bees varied widely across orchards (Figure 1b).

\subsection{Per-visit effectiveness and free-foraging behavior}

Per-visit effectiveness varied among interviewed Bombus, Melandrena, and Apis (Kruskal-Wallis, $\left.\chi_{2}^{2}=10.62, P=0.005\right)$. On average, Melandrena and Bombus deposited 2.5 and 1.5 times more pollen per-visit, respectively, than did Apis (Figure 2). Regardless of visitor identity, topworking and nectar-foraging bees deposited more pollen than side-working and pollenforaging bees (Table II). After controlling for the influence of flower handling and reward sought, some unmeasured characteristic(s) of Melandrena resulted in higher pollen deposition (significant pollinator effect; Table II).

During observations of natural foraging behavior among tree rows, Apis side-worked apple flowers 
a

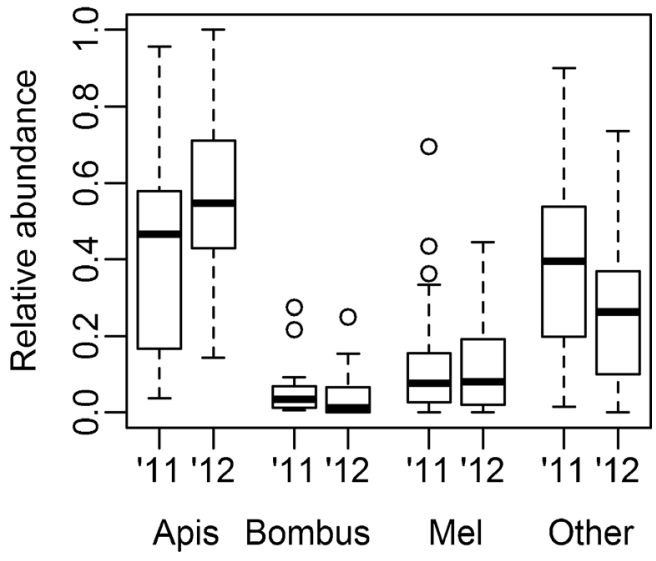

b

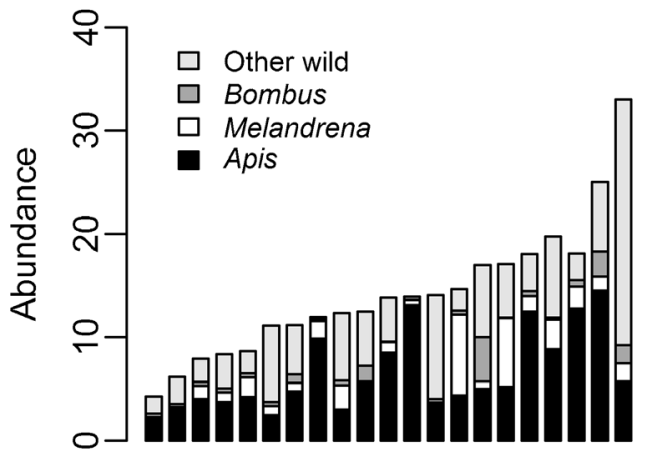

Farm

Figure 1. Relative abundance study-wide in 2011 and 2012 (a) and average abundance per transect per orchard across years (b) of Apis mellifera, Melandrena spp., Bombus spp., and all other wild bees.

disproportionately more than Melandrena (Fisher's exact, 2010: $P<0.001$; Pearson's, 2011: $\chi^{2}{ }_{1}=23.3$, $P<0.001$ ) and Bombus (Fisher's exact, $P=0.01$; see Table III for summary of all foraging data). Compared to Apis, Melandrena foraged for pollen more frequently (Fisher's exact, $P<0.001$ ), while Bombus sought pollen at similar rates (Fisher's exact, $P=1$ ). Visit duration of Bombus was half that of Apis, while that of Melandrena was twice as long (Wilcoxon rank sum, 2010: Bombus, $P=0.004$; Melandrena , $P<0.001$; Pearson's, 2011: $\left.\chi_{1}^{2}=23.3, P<0.001\right)$. As with natural visits, Apis side-worked interview flowers more often than Melandrena (Fisher's exact, $P<0.001$ ), but not Bombus (Fisher's exact, $P=0.2$ ). In general, more bees foraged for nectar only at interview flowers; Apis spent twice as long and

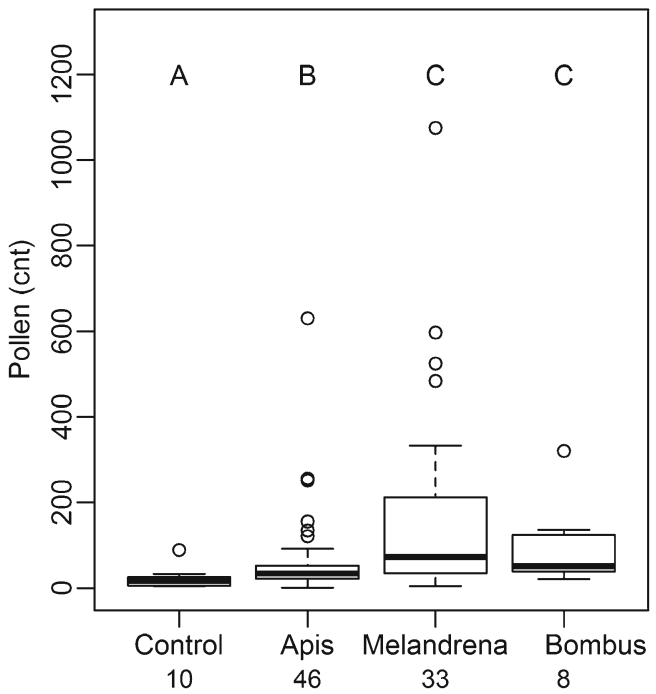

Figure 2. Number of Rosaceae pollen grains deposited on stigma after a single visit to emasculated flowers by three bee groups studied: Apis mellifera, Melandrena spp., and Bombus spp. at the Cornell University study orchard. Pollen counts on negative controls are also provided. Numbers below $x$-axis labels indicate sample size. Columns labeled with the same letter are not significantly different.

Melandrena half as long, on average, at interview flowers than they did at natural flowers (Table III).

\subsection{Per-visit efficiency and pollinator importance}

Fruit and seed set resulting from hand-applied Apis did not differ significantly from those resulting from hand-applied Melandrena or Bombus (GLMM: $\mathrm{t}_{26}=1.07, P=0.29$; Figure 3a, b). Melandrena applications, however, produced significantly larger fruitlets (Bombus v. Melandrena: $4.33 \mathrm{~g} \pm 0.059$ v. $4.56 \mathrm{~g} \pm 0.048$; GLMM: $\left.t_{27}=3.30, P<0.01\right)$ with higher seed set (Bombus v. Melandrena: $0.61 \pm 0.058$ v. 0.43 \pm 0.081 [mean \pm SEM]; Tukey's adjusted: $P=0.04$; Figure 3b) than Bombus applications. Such differences in fruit quality mirrored differences in pollen deposition (Figure 3c) by hand-applied Melandrena and Bombus (Tukey's adjusted, $P=0.02$; Table IV). Increasing with scopal pollen load size (Table IV), pollen deposition also had a positive effect on the number of carpels with developed seeds (GLMM: $t_{77}=2.20, P=0.03$ ). 
Table II. Significant effects of foraging behaviors and pollinator identity on per-visit pollen deposition on apple flowers from bee interviews in 2010 at Cornell University orchards. Due to low sample size for Bombus $(\mathrm{n}=8)$, only Apis $(\mathrm{n}=46)$ and Melandrena $(\mathrm{n}=33)$ were included. Approach refers to whether a bee side- or top-worked the flowers and reward refers to whether bees collected pollen or nectar. Non-significant interactions, visit duration, and presence of pollen load were excluded from final negative binomial model with $d f=73$

\begin{tabular}{llcll}
\hline Effect & Coeff. $( \pm$ SE $)$ & $Z$ value & $P$ value & Significant differences \\
\hline Pollinator & $0.99 \pm 0.26$ & 3.854 & 0.00012 & Melandrena $>$ Apis \\
Approach & $-0.78 \pm 0.26$ & -2.97 & 0.0030 & Top $>$ side \\
Reward & $-0.87 \pm 0.29$ & -3.045 & 0.0023 & Nectar $>$ pollen \\
\hline
\end{tabular}

Modeling relationships between pollen deposition and fruiting response showed that both fruit and seed set were optimized by higher pollen loads on stigmas, regardless of bee or pollen placement, and followed a positive, saturating curve (GLM or GLMM, fruit set CU: $Z_{43}=3.14, P<0.01$; NS: $Z_{62}=2.92, P<0.01$; seed set NS: $t_{20}=3.44$, $P<0.01$; Figure 4$)$. The non-significant $(P>0.05)$ fixed effects of pollinator, pollinator $\times$ pollen deposition, and pollen placement, reduced from full fruit and seed set GLM and GLMMs through backwards deletion, indicate that (1) bees carried similar quality pollen and (2) pollen stored in the scopa was as viable as pollen from the thorax.

Using relationships between pollen deposition and fruiting response, we translated per-visit effectiveness of interviewed bees to per-visit efficiency and observed significant but less dramatic differences in per-visit pollinator performance among bee groups (Kruskal-Wallis, seed and fruit set: $P<0.01$; Figure 5). Melandrena, but not Bombus, was more efficient than Apis (Wilcoxon rank sum, seed and fruit set: $P=0.007$ ) but not by 2.5 -fold as per-visit effectiveness suggested.

Orchard-level pollinator importance varied among focal bees (Kruskal-Wallis, 2011: $\chi_{2}^{2}=21.80, P<0.0001 ; 2012: \chi_{2}^{2}=44.66$, $P<0.0001$, Figure 6). Apis had significantly higher pollinator importance than both Melandrena (Wilcoxon rank sum, 2011: $P<0.05$; 2012: $P<0.0001)$ and Bombus (Wilcoxon rank sum, 2011 and 2012: $P<0.0001)$. Melandrena pollinator importance was significantly higher than that of Bombus in 2012 (Wilcoxon rank sum: $P=0.002$ ).

\section{DISCUSSION}

As honey bee declines decrease the availability and increase the cost of honey bee pollination for apple growers, the question of whether growers can rely on wild bees to fill the pollination gap becomes increasingly relevant. Per-visit, we found wild Bombus and Melandrena bees to be as efficient pollinators as Apis. Although Melandrena and Bombus contributed more to pollination than did Apis at two of our study orchards, the average importance of Melandrena and Bombus was small in comparison to Apis within the study region, due to the low relative abundances of these bees. Given their functional equivalence, Melandrena and Bombus have the potential to buffer some, but perhaps not all, honey bee losses, and only in orchards in which these bees are abundant.

The potential for inaccurately estimating the value of pollination in our system based on pollen transfer alone demonstrates the need to consider both pollinator efficiency and relative abundance. Based on pollen transfer alone, wild bees were more effective per-visit; however, translating pollinator effectiveness to efficiency revealed that pollinator performance was similar among our focal bees at the level of a single visit (Cane and Schiffhauer 2003). Previous work identifying Melandrena and Bombus as alternative pollinators of apple relied on pollen deposition and other proxies of pollinator efficiency: higher pollen transfer by Bombus compared with Apis (Thomson and Goodell 2001); high body counts and proportions of apple pollen found on Bombus and andrenids, notably Melandrena (Boyle and 
Table III. Frequencies of foraging behaviors for free-flying Apis mellifera, Melandrena spp., and Bombus spp. observed in 2010 and 2011 at Cornell University orchards. Foraging data for Bombus at natural flowers in 2011 are not available. Data are $\%$, means $( \pm \mathrm{SEM})$, or medians (min-max). Statistical tests compare foraging behaviors among all bee groups available, with mixed behavior reclassified as either top work or pollen

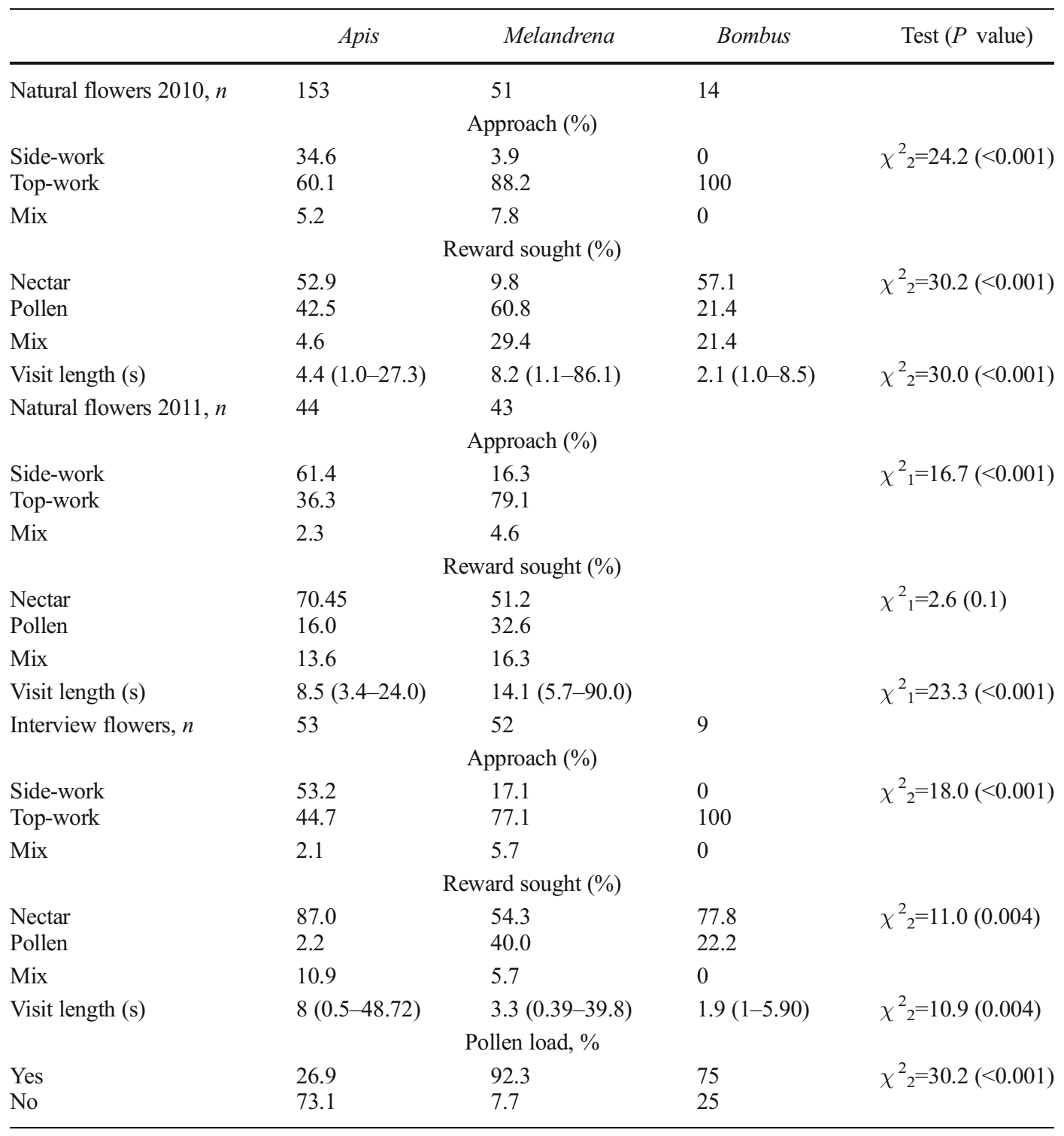

Philogene 1983; Kendall and Solomon 1973); and higher levels of Bombus and andrenid activity at lower temperatures (Boyle and Philogene 1983; Boyle-Makowski 1987). Our study confirms that Bombus and Melandrena are good pollinators of apple. Compared with Apis, Bombus and
Melandrena transferred roughly 150 to $250 \%$ more pollen per visit, but because of a saturating relationship between pollen deposition and reproductive success, the highest rates of pollen transfer to stigmas by Melandrena and Bombus were superfluous. Per-visit efficiency for 

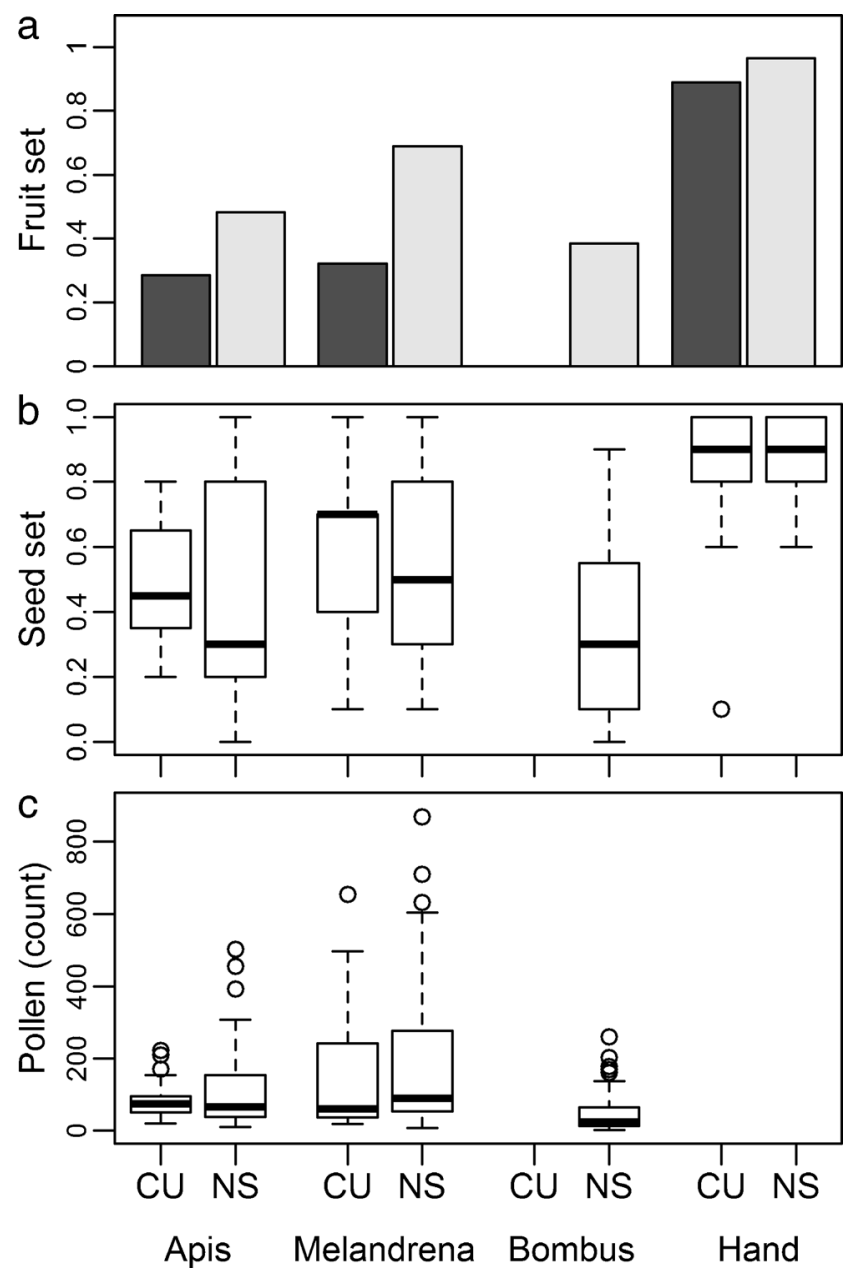

Figure 3. Proportion flowers that developed into fruit (a), proportion seeds that developed within a fruit (b), and stigmatic pollen loads (c) resulting from applying the underside of immobilized bees and a positive control ("Hand" applied pure cross pollen) to stigmas of experimental apple flowers at Cornell University (CU) and Nova Scotia (NS) study orchards. Note: Bombus were not applied to blossoms at CU. Sample size for Apis mellifera, Melandrena spp., Bombus spp., and positive control were as follows: $\mathrm{CU}$ fruit set=28, 28, NA, 27 and seed set=8, 24, 9, NA; NS fruit set=29, 29, 26, 29; and seed set=14, 19, 10, 27.

Melandrena, based on per-visit fruit and seed set estimates, was only $20 \%$ higher than Apis and efficiency of Bombus was equivalent to that of Apis . Contrary to predictions, pollen quality was similar among bees, meaning bees move throughout the orchard similarly or that only recently acquired pollen is transferred to apple stigmas. Using per-visit efficiency rather than pollen deposition, per se, improved our assessment of pollinator performance among specific bee groups; however, we may still provide a simplified view of pollination as we did not capture differences in visitation rates or in diurnal or temperature patterns of activity (Boyle and Philogene 1983; Phillips 1933).

Our results demonstrate that when assessing pollinator quality for apple, higher pollen transfer is desirable within the bounds of an upper threshold. High pollen transfer has predictable benefits for crops whose fruits require fertilization of many ovules, such as strawberry (Klatt et al. 2014). However, as has been previously found with 
Table IV. Significant effects of pollinator identity and pollen load size on (ln-transformed) per-visit pollen deposition resulting from hand-applied Apis, Melandrena, and Bombus on apple flowers in 2011 at Cornell University (CU) and Nova Scotia (NS) orchards. At NS, tree was included as a random blocking factor. At NS, whether pollen came from the thorax or scopa was not significant and was excluded from final GLMM. Degrees of freed from CU GLM and NS GLMM were 39 and 107, respectively. Coefficients are not back-transformed

\begin{tabular}{|c|c|c|c|c|c|c|}
\hline \multirow[t]{2}{*}{ Effect } & \multicolumn{3}{|c|}{$\mathrm{CU}$} & \multicolumn{3}{|c|}{ NS } \\
\hline & coeff. $( \pm$ SE) & t-value & $P$-value & coeff. $( \pm$ SE) & t-value & $P$-value \\
\hline \multicolumn{7}{|c|}{ Pollinator $(\mathrm{ref}=$ Apis $)$} \\
\hline Melandrena & $0.011 \pm 0.21$ & 0.045 & 0.96 & $0.34 \pm 0.20$ & 1.66 & 0.10 \\
\hline Bombus & & & & $-0.27 \pm 0.23$ & -1.17 & 0.25 \\
\hline \multicolumn{7}{|c|}{ Pollen load size (ref=none) } \\
\hline Small & $0.33 \pm 0.28$ & 1.17 & 0.24 & $0.74 \pm 0.31$ & 2.39 & 0.019 \\
\hline Medium & $0.90 \pm 0.30$ & 2.99 & 0.0049 & $1.27 \pm 0.24$ & 5.26 & $<0.0001$ \\
\hline Large & $1.90 \pm 0.44$ & 4.32 & 0.0010 & $1.56 \pm 0.26$ & 5.83 & $<0.0001$ \\
\hline
\end{tabular}

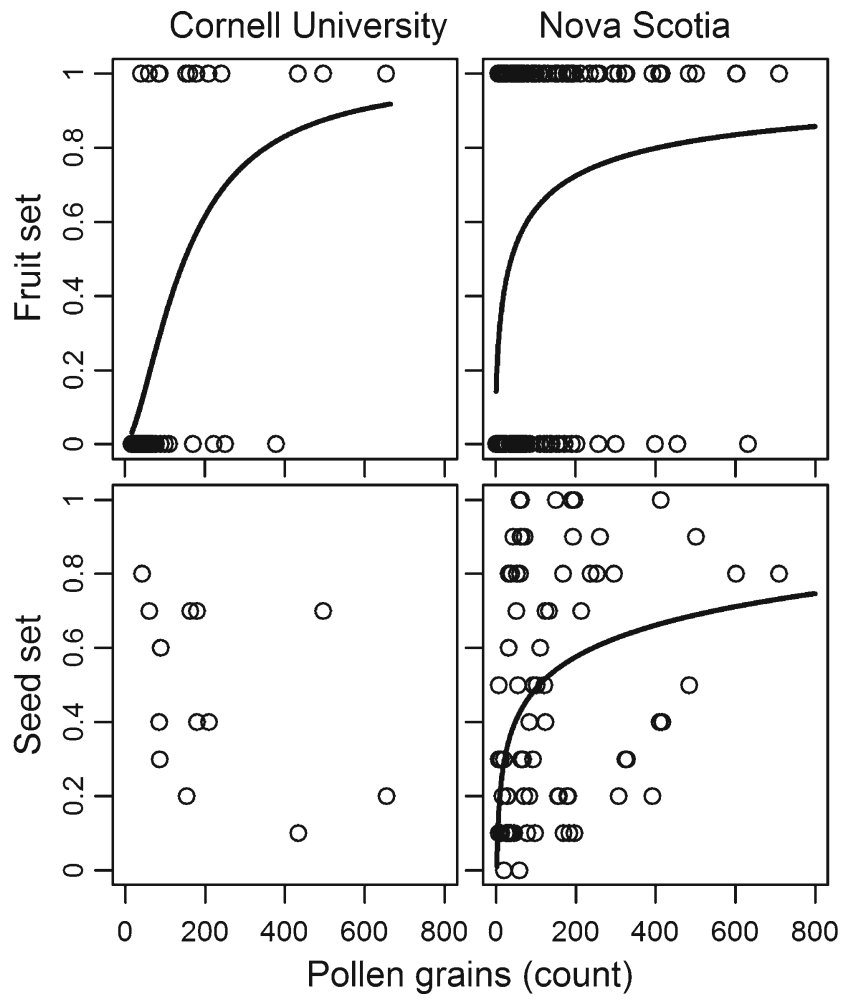

Figure 4. Relationships between stigmatic pollen loads deposited by hand-applied bees and reproductive success (both probability of fruit and seed development) at study orchards. 
a
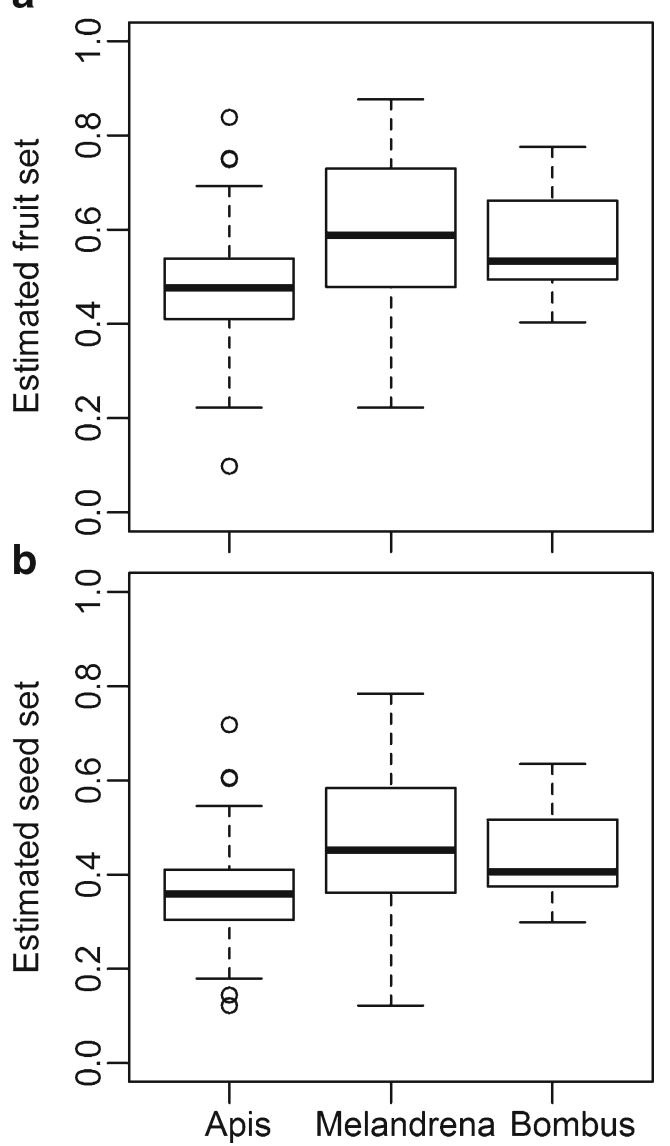

Figure 5. Estimated per-visit probabilities of fruit (a) and seed set (b) for Apis mellifera, Melandrena spp., and Bombus spp. based on free-flying bee pollen deposition and relationships between pollen deposition and reproductive success at NS.

cherry and almond, we found that even for apple, with only ten ovules per fruit, the amount of pollen transferred had a strong, positive influence on fruit quantity and quality (Bosch and Blas 1994; Holzschuh et al. 2012). Hand-applied gradients of cross-pollen loads to apple stigmas showed the same positive relationship between pollen load and fruit development, with optimal pollen-tube growth achieved with 40 germinating pollen grains per stigma (or 200 grains per flower; Janse and Verhaegh 1993). Mechanistically, higher loads of viable pollen could optimize reproductive

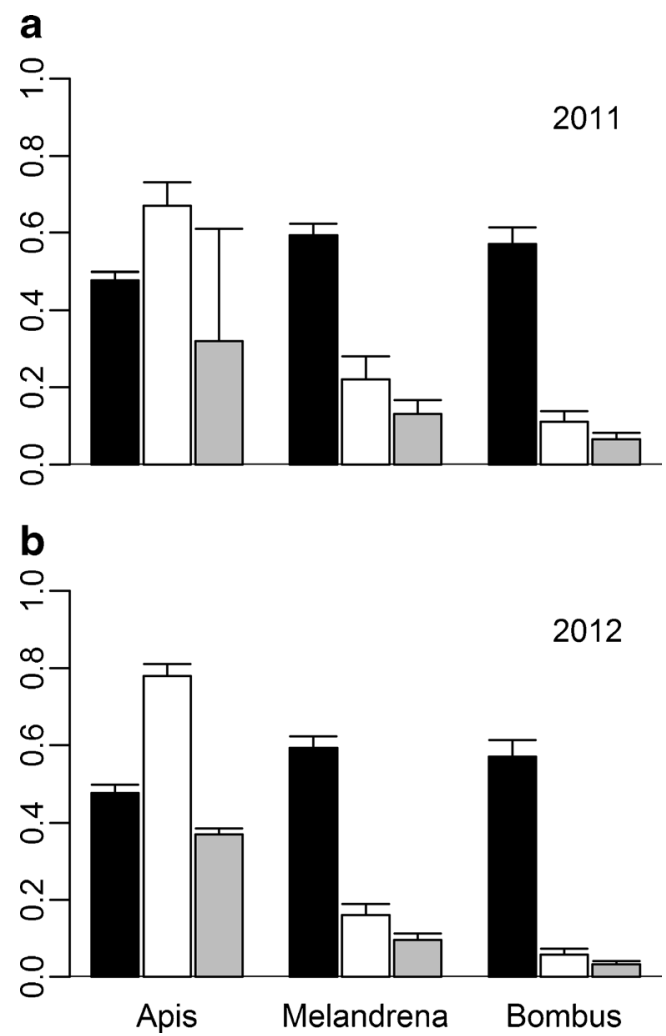

Figure 6. Per-visit efficiency (i.e., estimated fruit set, black), relative pollinator abundance (white), and pollinator importance (gray) of three focal bees visiting apple in 2011 (a) and 2012 (b). Data are means+1SE.

success by priming stigmas (Janse and Verhaegh 1993; Visser 1981), distributing pollen among stigmas (Free 1993; Sheffield et al. 2005), and/or reducing stigmatic clogging (Shore and Barrett 1984). For crops that are self-incompatible, if similar relationships between pollen deposition and efficiency are established, further assessment of pollinator efficiency could be readily derived from pollen deposition. Even though establishing such relationships is time and labor-intensive, so is counting pollen tubes using fluorescence microscopy, the only other way to accurately estimate per-visit pollinator performance for specific pollinators (Brittain et al. 2013).

Our results validate the use of bee attributes that influence pollen transfer, specifically 
handling behavior, pollen counts on bodies and pollen placement, as proxies for apple pollinator efficiency. First, as observed by Thomson and Goodell (2001), when bees top-worked Honeycrisp flowers, stigma contact increased, resulting in higher pollen deposition. Side-working, a form of nectar robbing, is a learned behavior used primarily by nectar-foraging Apis, which growers can manage only by introducing naive colonies to orchards sequentially (Stern et al. 2007). Solitary wild bees are less likely to sidework because they are primarily foraging for pollen and, therefore, have no reason to avoid anthers (Westerkamp 1991). Generally, pollen foragers have more pollen on their bodies and, therefore, transfer more pollen (Free 1993); however, nectar foraging resulted in higher pollen deposition among interviewed bees. We attribute this discrepancy to removal of anthers from experimental flowers, which may have altered pollen foraging behavior, or to larger quantities of nectar in virgin flowers, which encouraged Apis to forage longer on interview than natural flowers. Such a behavioral change among nectaring Apis, could have inflated pollinator effectiveness and, therefore, efficiency of this managed bee. Second, observations that pollen deposition increased with size of pollen load support the use of body pollen counts to identify, but may not be resolved enough to rank quality pollinators for apple. Scopal pollen directly applied to stigmas was as viable for fertilization as thoracic pollen in this study. For Bombus and Apis, likelihood of corbicular pollen contacting stigmas is low, therefore, pollen load size was more likely a proxy for how much pollen was on the rest of the bodies of these bees. Pollen placement is likely to be more important than load size, per se. Melandrena store their pollen dry in scopae near the abdomen and within the trochanteral and femoral scopa at the base of each hind leg, where pollen may more readily transfer to stigmas. Similarly, dry pollen stored by Osmia bees in a ventral, abdominal scopa results in high pollinator efficiency (Kuhn and Ambrose 1984; Sheffield 2014; Vicens and Bosch 2000). Regardless of their size, bees that store pollen on their bodies in a manner that maximizes stigmatic transfer will predictably perform well, as long as they carry viable pollen. Andrenids, which comprised $40 \%$ of the number of wild bees visiting apple and varied greatly in size, are likely efficient apple pollinators for this very reason.

We find that, at their current abundances, neither Melandrena nor Bombus would replace the level of pollination services presently provided by managed honey bees across our study region; however, several factors support the potential for growers to already rely more on wild bees and less on Apis. First, Melandrena and Bombus represent but a subset of more than 100 wild bee species found visiting apple in five years of survey data from central New York apple orchards (Russo et al. 2015). While these two bee groups alone may not substitute for Apis, because so many other wild bees visit apple (Figure 1b) further study is needed before we rule out the possibility that wild bee communities can provide all the necessary pollination even if honey bee pollination continues to decline. Second, as is the case for a suite of crops worldwide, apple production (i.e., fruit set) is positively influenced by wild bee abundance and species richness, but not Apis abundance (Blitzer et al. unpubl. data; Garibaldi et al. 2013; Mallinger and Gratton 2015). Such disconnect between fruit production and Apis implies that there may already be more Apis brought into orchards than is necessary due to the activity of wild pollinators. If true, then our calculations of pollinator importance, primarily influenced by relative abundances, may be skewed by widespread supplementation of honey bees within our study system. Third, apple orchards in central New York are regularly over-pollinated, as evidenced by the ubiquitous practice of thinning tree fruit load shortly after initial fruit set (Robinson et al. 2013). Such practice further supports that wild pollinators need not necessarily be as abundant as Apis to provide adequate pollination. Finally, wild bee abundance is not static and can be augmented. We observed high spatial and temporal variation in wild bee abundance across orchards (Figure 1b). Bee abundance is positively tied to access to natural 
habitat and depressed with increasing intensity of pesticide regimes in orchards (Kennedy et al. 2013; Martins et al. 2015; Park et al. 2015; Watson et al. 2011). Therefore, growers have tools to increase wild bee abundance within their orchard, if desired.

Wild bees may also increase fruit yield in ways that cannot be captured in our study. Wild pollinators complement Apis pollination of apple by handling flowers differently while foraging, by visiting flowers in different parts of the tree canopy, and/or by changing Apis foraging behavior in a manner that improves its pollinator performance (Brittain et al. 2013; Martins et al. 2015). Boyle-Makowski (1987) found native bees, particularly Andrena and halictids, to be important apple pollinators during years of poor weather since honey bee visitation was low under these conditions. The value of wild pollinators compared to honey bees was similarly high on windy days, when Apis would not visit almond blossoms but wild bees would (Brittain et al. 2013). Optimal bee density will be context and crop specific, varying with bloom density, distance of pollen source, as well as amount of competing floral resources surrounding the focal crop (Brittain 1933). Development of protocols that monitor native bee abundance in a context-specific, reliable, and easy manner is central to providing growers with the information they need to assess native pollination services available to them.

Honey bees are important for apple production, and arguably are essential for large, intensively managed orchards with little adjacent natural habitat to support wild pollinators. Wild bees, however, are as efficient and likely contribute more to apple pollination than growers currently realize. Transitioning an orchard to rely more heavily on wild pollinators may require actions on the grower's part to increase and maintain wild bee abundance. Growers may optimize wild bee abundance by maximizing natural areas surrounding their orchards, decreasing pesticide intensity, and creating additional habitat and foraging resources for bees near orchards (Kennedy et al. 2013; Park et al. 2015; Watson et al. 2011). This study continues to build on a growing body of evidence that wild bees benefit crop production and may buffer against declines in Apis populations.

\section{ACKNOWLEDGMENTS}

We are grateful for the assistance of C. Embree, D. Nichols, and D. Moreau, at the Atlantic Food and Horticulture Research Center, Agriculture and AgriFood Canada, Kentville, Nova Scotia. We thank the collaborating apple growers and managers for their permission to survey the orchards. Many people helped in the field: E. J. Blitzer, J. Hudgins, L. Moshman, M. Orr, K. San-Miguel, C. Remick, E. Hurme, J. Moiseff, J. Cappadona, L. Duque, N. Adamson, S. Hartwick, S. Villarreal, A. Debevec, G. Montgomery, and J. Brokaw. J Gibbs kindly helped to identify bees. F. Vermeylan provided guidance in statistical analyses. J. Thomson and $\mathrm{H}$. Reissig provided insightful comments on earlier drafts. We appreciate comments provided by three anonymous reviewers, which significantly improved the clarity of the manuscript. This project was supported by Smith Lever and Hatch Funds administered by Cornell University Agricultural Experiment Station and by a USDA-AFRI grant [USDA 2010-03689, B.N. Danforth, PI]. M.G. Park received additional support from the Palmer, Rawlins, and Chapman awards in the Department of Entomology and a Land Grant Extension Fellowship from the College of Agriculture and Life Sciences at Cornell University.

OPEN ACCESS This article is distributed under the terms of the Creative Commons Attribution 4.0 International License (http://creativecommons.org/licenses/by/4.0/), which permits unrestricted use, distribution, and reproduction in any medium, provided you give appropriate credit to the original author(s) and the source, provide a link to the Creative Commons license, and indicate if changes were made.

Performance pollinisatrice "par visite" et importance régionale des populations sauvages de Bombus et d'Andrena (Melandrena), comparées aux abeilles des ruchers industriels, dans les vergers de pommiers de l'Etat de New York

abeille indigène / Apis mellifera / succès reproducteur / pollinisation des cultures

Bestäubungsleistung pro Blütenbesuch und regionale Bedeutung von wildlebenden Bombus und Andrena (Melandrena) im Vergleich zu imkerlich gehaltenen Honigbienen in Apfelanlagen in New York

Einheimische Bienen / Apis mellifera / Reproduktionserfolg / Bestäubung 


\section{REFERENCES}

Artz, D.R., Nault, B.A. (2011) Performance of Apis mellifera, Bombus impatiens, and Peponapis pruinosa (Hymenoptera: Apidae) as pollinators of pumpkin. J. Econ. Entomol. 104, 1153-61

Bates, D., Maechler, M., Bolker, B. (2011) lme4: Linear mixed-effects models using s4 classes [online] http://cran.R-project.org/package=lme4. R package version 1.1-7

Benjamin, F.E., Winfree, R. (2014) Lack of pollinators limits fruit production in commercial blueberry (Vaccinium corymbosum). Environ. Entomol. 43 (6), 1574-83

Bosch, J., Blas, M. (1994) Foraging behaviour and pollinating efficiency of Osmia cornuta and Apis mellifera on almond (Hymenoptera, Megachilidae and Apidae). Appl. Entomol. Zool. 29(1), 1-9

Boyle, R.M.D., Philogene, B.J.R. (1983) The native pollinators of an apple orchard: variations and significance. J. Hortic. Sci. 58(3), 355-63

Boyle-Makowski, R.M.D. (1987) The importance of native pollinators in cultivated orchards: their abundance and activities in relation to weather conditions. Proc. Entomol. Soc. Ont. 118, 125-41

Breeze, T.D., Vaissière, B.E., Bommarco, R., Petanidou, T., Seraphides, N., et al. (2014) Agricultural policies exacerbate honeybee pollination service supply-demand mismatches across Europe. PLoS ONE 9 (1), e82996

Brittain, C., Williams, N., Kremen, C., Klein, A.-M. (2013) Synergistic effects of non-Apis bees and honey bees for pollination services. Proc. R. Soc. B Biol. Sci 280 (1754), 20122767

Brittain, W.H. (1933) Apple pollination studies in the Annapolis Valley, NS, Canada. Bull. Dep. Agric. Can. New. Ser. 162

Brittain, W.H. (1935) Studies in bee activity during apple bloom. J. Econ. Entomol. 28, 553-59

Cane, J.H., Schiffhauer, D. (2003) Dose-response relationships between pollination and fruiting refine pollinator comparisons for cranberry (Vaccinium macrocarpon [Ericaceae]). Am. J. Bot. 90 (10), 1425-32

Free, J.B. (1993) Insect Pollination of Crops, 2nd edn. Academic Press Ltd., London

Gallai, N., Salles, J.-M., Settele, J., Vaissière, B.E. (2009) Economic valuation of the vulnerability of world agriculture confronted with pollinator decline. Ecol. Econ. 68(3), 810-21

Gardner, K.E., Ascher, J.S. (2006) Notes on the native bee pollinators in New York apple orchards. J. N. Y. Entomol. Soc. 114(1), 86-91

Garibaldi, L.A., Steffan-Dewenter, I., Winfree, R., Aizen, M.A., Bommarco, R., et al. (2013) Wild pollinators enhance fruit set of crops regardless of honey bee abundance. Science 339 (6127), 1608-11

Garratt, M.P.D., Breeze, T.D., Jenner, N., Polce, C., Biesmeijer, J.C., Potts, S.G. (2014) Avoiding a bad apple: insect pollination enhances fruit quality and economic value. Agric. Ecosyst. Environ. 184, 34-40

Harder, L.D., Thomson, J.D. (1989) Evolutionary options for maximizing pollen dispersal of animal-pollinated plants. Am. Nat. 133 (3), 323-44

Hoehn, P., Tscharntke, T., Tylianakis, J.M., SteffanDewenter, I. (2008) Functional group diversity of bee pollinators increases crop yield. Proc. R. Soc. B Biol. Sci. 275 (1648), 2283-91

Holzschuh, A., Dudenhöffer, J.-H., Tscharntke, T. (2012) Landscapes with wild bee habitats enhance pollination, fruit set and yield of sweet cherry. Biol. Conserv. 153, $101-7$

Janse, J., Verhaegh, J.J. (1993) Effects of varying pollen load on fruit set, seed set and seedling performance in apple and pear. Sex. Plant Reprod. 6(2), 122-26

Javorek, S.K., Mackenzie, K.E., Vander Kloet, S.P. (2002) Comparative pollination effectiveness among bees (Hymenoptera: Apoidea) on lowbush blueberry (Ericaceae: Vaccinium angustifolium ). Ann. Entomol. Soc. Am. 95 (3), 345-51

Kearns, C.A., Inouye, D.W. (1993) Techniques for Pollination Biologists. University Press of Colorado, Boulder, CO

Kendall, D.A., Solomon, M.E. (1973) Quantities of pollen on the bodies of insects visiting apple blossom. J. Appl. Ecol. $10(2), 627-34$

Kennedy, C. M., Lonsdorf, E., Neel, M.C., Williams, N.M., Ricketts, T.H., et al. (2013) A global quantitative synthesis of local and landscape effects on wild bee pollinators in agroecosystems. Eco. Letters 16(5), 584-599

Klatt, B.K., Holzschuh, A., Westphal, C., Clough, Y., Smit, I., et al. (2014) Bee pollination improves crop quality, shelf life and commercial value. Proc. R. Soc. B Biol. Sci. 281 (1775), 20132440

Kremen, C., Williams, N.M., Thorp, R.W. (2002) Crop pollination from native bees at risk from agricultural intensification. Proc. Natl. Acad. Sci. 99 (26), 16812-16

Kuhn, E.D., Ambrose, J.T. (1984) Pollination of "Delicious" apple by megachilid bees of the genus Osmia (Hymenoptera: Megachilidae). J. Kans. Entomol. Soc. 57 (2), 169-80

Mallinger, R.E., Gratton, C. (2015) Species richness of wild bees, but not the use of managed honeybees, increases fruit set of a pollinator-dependent crop. J. Appl. Ecol. $52(2), 323-30$

Martins, K., Gonzalez, A., Lechowicz, M.J. (2015) Pollination services are mediated by bee functional diversity and landscape context. Agric. Ecosyst. Environ. 200, 12-20

McGregor, S.E. (1976) Insect Pollination of Cultivated Crop Plants. U.S. Department of Agriculture, Agricultural Research Service [online] http:// www.ars.usda.gov/SP2UserFiles/Place/20220500/ OnlinePollinationHandbook.pdf

Ne'eman, G., Jürgens, A., Newstrom-Lloyd, L., Potts, S.G., Dafni, A. (2010) A framework for comparing pollinator performance: effectiveness and efficiency. Biol. Rev. 85(3), 435-51 
Oldroyd, B.P. (2007) What's killing American honey bees? PLoS Biol. 5, e168

Olsen, K.M. (1996) Pollination effectiveness and pollinator importance in a population of Heterotheca subaxillaris (Asteraceae). Oecologia 109(1), 114-21

Park, M.G., Danforth, B.N., Orr, M.C. 2010. The role of native bees in apple pollination. N. Y. Fruit Q., 21-25

Park, M.G., Blitzer, E.J., Gibbs, J., Losey, J.E., Danforth, B.N. (2015) Negative effects of pesticides on wild bee communities can be buffered by landscape context. Proc. R. Soc. B Biol. Sci. 282, 20150299

Phillips, E.F. (1933) Insects collected on apple blossoms in western New York. J. Agric. Res. 46, 851-62

Pinheiro, J., Bates, D., Sarkar, D., R Core Team (2014) nlme: Linear and nonlinear mixed effects models [online] http://CRAN.R-project.org/package=nlme. R package version 3.1-118.

Powell, L.A. (2007) Approximating variance of demographic parameters using the delta method: a reference for avian biologists. The Condor 109 (4), 949-54

Rader, R., Howlett, B.G., Cunningham, S.A., Westcott, D.A., Newstrom-Lloyd, L.E., et al. (2009) Alternative pollinator taxa are equally efficient but not as effective as the honeybee in a mass flowering crop. J. Appl. Ecol. 46, 1080-1087

Ricketts, T.H. (2004) Tropical forest fragments enhance pollinator activity in nearby coffee crops. Conserv. Biol. 18(5), 1262-71

Robinson, T., Lakso, A.N., Greene, D., Hoying, S. (2013) Precision crop load management. N. Y. Fruit Q. 21 (2), 6-9

Robinson, W.S., Fell, R.D. (1981) Effect of honey bee foraging behaviors on "Delicious" apple set and development. Hortic. Sci. 16(3), 326-28

Russo, L., Park, M.G., Gibbs, J., Danforth, B.N. (2015) The challenge of accurately documenting bee species richness in agroecosystems: bee diversity in eastern apple orchards. Ecol. Evol (in press).

Sheffield, C.S. (2014) Pollination, seed set and fruit quality in apples: studies with Osmia lignaria (Hymenoptera: Megachilidae) in the Annapolis valley, Nova Scotia, Canada. J. Pollinat. Ecol. 12 (13), 120-128

Sheffield, C.S., Smith, R.F., Kevan, P.G. (2005) Perfect syncarpy in apple (Malus $\times$ domestica "Summerland McIntosh") and its implications for pollination, seed distribution and fruit production (Rosaceae: Maloideae). Ann. Bot. 95 (4), 583-91

Shore, J.S., Barrett, S.C.H. (1984) The effect of pollination intensity and incompatible pollen on seed set in Turnera ulmifolia (Turneraceae). Can. J. Bot. 62 (6), 1298-1303

Snow, A.A. (1982) Pollination intensity and potential seed set in Passiflora vitifolia. Oecologia. 55 (2), 231-37

Stern, R., Sapir, G., Shafir, S., Dag, A., Goldway, M. (2007) The appropriate management of honey bee colonies for pollination of Rosaceae fruit trees in warm climates. Middle East. Russ. J. Plant Sci. Biotechnol. 1 (1), 1319

Thomson, J.D., Goodell, K. (2001) Pollen removal and deposition by honeybee and bumblebee visitors to apple and almond flowers. J. Appl. Ecol. 38(5), 1032-44

Thorp, R. (2000) The collection of pollen by bees. In: Dafni, A., Hesse, M., Pacini, E. (eds.) Pollen and Pollination, pp. 211-23. Springer, Vienna

vanEngelsdorp, D., Evans, J.D., Saegerman, C., Mullin, C., Haubruge, E., et al. (2009) Colony Collapse Disorder: A descriptive study. PLoS ONE 4 (8), e6481

Vázquez, D.P., Morris, W.F., Jordano, P. (2005) Interaction frequency as a surrogate for the total effect of animal mutualists on plants. Ecol. Lett. 8(10), 1088-94

Venables, W.N., Ripley, B.D. (2002) Modern applied statistics with S, 4th edn. Springer, New York

Vicens, N., Bosch, J. (2000) Pollinating efficacy of Osmia cornuta and Apis mellifera (Hymenoptera: Megachilidae, Apidae) on 'Red Delicious' apple. Environ. Entomol. 29(2), 235-40

Visser, T. (1981) Pollen and pollination experiments IV. "Mentor pollen" and "pioneer pollen" techniques regarding incompatibility and incongruity in apple and pear. Euphytica $30(2), 363-69$

Watson, J.C., Wolf, A.T., Ascher, J.S. (2011) Forested landscapes promote richness and abundance of native bees (Hymenoptera: Apoidea: Anthophila) in Wisconsin apple orchards. Environ. Entomol. 40 (3), 621-32

Westerkamp, C. (1991) Honeybees are poor pollinatorswhy? Plant Syst. Evol. 177 (1-2), 71-75

Zuur, A.F., Hilbe, J.M., Leno, E.N. (2013) A Beginner's Guide to GLM and GLMM with R: A Frequentist and Bayesian Perspective for Ecologists. Highland Statistics Ltd., Newburgh, UK 